\title{
Occupational Exposure to Aromatic Hydrocarbons at a Coke Plant: Part II. Exposure Assessment of Volatile Organic Compounds
}

\author{
Grażyna Bieniek, Sławomir Kurkiewicz, Tadeusz Wilczok, Katarzyna Klimek, \\ Longina SwiA̧TKOWsKa and Agnieszka Lusiak
}

Department of Molecular Biology, Biochemistry and Biopharmacy, Faculty of Pharmacy Medical University of Silesia, Poland

\begin{abstract}
Occupational Exposure to Aromatic Hydrocarbons at a Coke Plant: Part II. Exposure Assessment of Volatile Organic Compounds: Grażyna BIENiEk, et al. Department of Molecular Biology, Biochemistry and Biopharmacy, Faculty of Pharmacy Medical University of Silesia, PolandThe objective of the study is to assess the external and internal exposures to aromatic hydrocarbons in the tar and oil naphthalene distillation processes at a coke plant. 69 workers engaged as operators in tar and oil naphthalene distillation processes and 25 non-exposed subjects were examined. Personal analyses of the benzene, toluene, xylene isomers, ethylbenzene, naphthalene, indan, indene and acenaphthene in the breathing zone air allowed us to determine the time weighted average exposure levels to the aromatic hydrocarbons listed above. The internal exposure was investigated by measurement of the urinary excretion of naphthols, 2-methylphenol and dimethylphenol isomers by means of gas chromatography with a flame ionization detection (GC/FID). Urine metabolites were extracted after enzymatic hydrolysis by solid-phase extraction with styrene-divinylbenzene resin. The timeweighted average concentrations of the hydrocarbons detected in the breathing zone air shows that the exposure levels of the workers are relatively low in comparison to the exposure limits. Statistically significant differences between average concentrations of aromatic hydrocarbons (benzene, toluene, xylene isomers) determined at the workplaces in the tar distillation department have been found. Concentrations of the naphthalene and acenaphthene detected in workers from the oil distillation department are higher that those from the tar distillation department. Concentrations of naphthols, 2-methoxyphenol and
\end{abstract}

Received July 25, 2003; Accepted Jan 14, 2004

Correspondence to: G. Bieniek, Department of Molecular Biology, Biochemistry and Biopharmacy, Faculty of Pharmacy Medical University of Silesia, Jagiellonska 4, 41-200, Sosnowiec, Poland (e-mail:maja@slam.katowice.pl) dimethylphenol isomers in the urine of occupationally exposed workers were significantly higher than those of non-exposed subjects. Concentrations of the 2methoxyphenol and dimethylphenol isomers in urine were significantly higher for the tar distillation workers, whereas concentrations of naphthols were higher for the oil naphthalene distillation workers. Operators at the tar and naphthalene oil distillation processes are simultaneously exposed to a mixture of different hydrocarbons, mainly benzene and naphthalene homologues.

(J Occup Health 2004; 46: 181-186)

Key words: Mixed exposure, Urinary metabolites, GC/ FID analysis

Coke plants are known as sources of aromatic and polycyclic hydrocarbons and many other chemicals ${ }^{1-4)}$. Tar and naphthalene oil distillation processes emit a complex mixture of vapour and gases. The exposure to chemicals is usually assessed by both environmental and biological monitoring. Determination of volatile solvents and their metabolites in biological materials such as expired air, blood or urine, makes it possible to estimate the exposure levels to specific organic compounds that contaminate the environment. Biological monitoring was used to assess the exposure via both skin absorption and the gastrointestinal system. Biological monitoring of the mixed exposure is a growing field of interest in many occupational and toxicological investigative laboratories ${ }^{3,5,6)}$. Mixed exposure to aromatic hydrocarbons has previously been investigated by many authors ${ }^{7-12}$.

The aim of the present study was to assess the mixed exposure of coke-plant workers to benzene and homologues, naphthalene, indane, indene and acenaphthene with air and biological monitoring. Biological monitoring was conducted by the analysis of urinary naphthols and phenols. 


\section{Methods and Materials}

\section{Subjects}

In this study, analyses were carried out in the summer months of 2001 and 2002. The investigated group comprised 69 workers, mean age 38 yr (range 20-65) exposed to aromatic hydrocarbons in a coke plant situated in Upper Silesia, Poland. Workers were engaged as operators in the tar distillation department (group A) and as operators in the naphthalene oil distillation department (group B). The survey was performed on the 5th day of a working week, by which time the metabolite excretion should have reached a plateau. The air and urine samples were collected on the same day during the day shift (6:00 AM-2:00 PM). To determine the physiological levels of urine phenols the 25 workers not occupationally exposed to aromatic hydrocarbons, mean age $28 \mathrm{yr}$ (range 18-59) were investigated as a control. All subjects were smokers.

\section{Air sampling and GC analysis of aromatic hydrocarbons}

Air samples were collected in the breathing zone of the workers during the work shift. The sampling systems included a sorbent tube (SKC 226-01 charcoal tube, 100 mg/50 mg, SKC Inc., Eighty-Four, PA) and a low-flow sampling pump (type AFC 122 Casella Ltd, London, UK). The sampling flow rate was $0.5 \mathrm{l} / \mathrm{min}$ for $6 \mathrm{~h}(180 \mathrm{l})$. After sample collection, the analytes were released from the charcoal by treatment with $1 \mathrm{ml}$ of carbon disulfidemethanol $(60: 1, \mathrm{v} / \mathrm{v})$ in an ultrasonic bath for $15 \mathrm{~min}$. The amount of the compound in the back-up showed no more than $10 \%$ of the compound in the sampling section. Otherwise the measurement was repeated.

Desorption efficiency for each target volatile compound was determined by analyzing three sorbent tubes. Each tube was spiked to the front section of the sorbent tube. Desorption efficiencies for benzene, toluene and xylene isomers were in the range 95-98\%, whereas for naphthalene it was equal to $50 \%$. The low desorption efficiencies for naphthalene were used for the concentration calculations.

The analysis of the charcoal extracts was performed with a Hewlett Packard, Model 5890 Series II gas chromatograph equipped with a flame ionization detector, an autosampler/autoinjector (HP7673) and an integrator (HP3396II) (Delaware, NY). Ethylbenzene, indan, indene and acenaphthene in air were analyzed gas chromatographically as previously described by Bieniek ${ }^{13)}$.

Aromatic hydrocarbons (naphthalene, benzene, toluene, $\mathrm{m}+\mathrm{p}$-xylene and o-xylene) were analysed as previously described by Cisowska, Lusiak and Siwek [unpublished data]. In the abovementioned method, a capillary column Ultra $2(25 \mathrm{~m} \times 0.32 \mathrm{~mm}$ I. D., $0.52 \mu \mathrm{m}$ film thickness (HP Part No. 19091 B-112) with injector and detector temperatures of 200 and $220^{\circ} \mathrm{C}$, respectively, was used. The following temperature program and GC parameters were applied: $40^{\circ} \mathrm{C}$ for $1 \mathrm{~min}$, increased by $12^{\circ} \mathrm{C} / \mathrm{min}$ to $140^{\circ} \mathrm{C}$; held for $2 \mathrm{~min}$; carrier gas, helium at a flow-rate of $2.5 \mathrm{ml} / \mathrm{min}$; injection volume, $1 \mu \mathrm{l}$; splitless time, 1 min; split ratio, 1:30.

Ten duplicate analyses were performed at the lowest concentration of the calibrating curve, for all hydrocarbons, and the detection limit of the hydrocarbons was determined as three times the magnitude of the resultant standard deviation. For benzene, toluene, o-xylene, $\mathrm{m}+\mathrm{p}$-xylene and naphthalene the following detection limits: $0.75,1.02$, 0.47, 0.86 and $0.67 \mathrm{ppb}$, quantitation limits: $2.45,3.57$, 1.58, 2.85 and $2.22 \mathrm{ppb}$, and precision: 9.6, 3.5, 3.9, 3.3 and $3.7 \%$ were obtained, respectively.

\section{Urinalysis}

Urine samples were collected from the exposed workers during the last $4 \mathrm{~h}$ of the work shift (10:00 AM to 2:00 PM). Samples were kept at $20^{\circ} \mathrm{C}$ until analysis. Each sample was then thawed, and $10 \mathrm{~m} l$ was transferred to an Erlenmayer flask. 1M hydrochloric acid solution was used to bring the sample to $\mathrm{pH} 5$, and $5 \mathrm{ml}$ of $0.1 \mathrm{M}$ pH 5 acetate buffer was added. $25 \mu l$ of $\beta$-glucuronidasearylosulfatase was added to each urine sample in order to hydrolyze conjugated metabolites. The solutions were incubated for $20 \mathrm{~h}$ at $37^{\circ} \mathrm{C} .15 \mathrm{ml}$ of the hydrolyzed sample was loaded onto SPE octadecyl $\left(\mathrm{C}_{18}\right)$ columns. The phenols were eluted with $3 \times 0.5 \mathrm{~m} l$ of methanolacetonitrile $(10: 1, \mathrm{v} / \mathrm{v})$ into vials. The solvent was evaporated to dryness under a stream of nitrogen. The elute was dissolved in $1 \mathrm{~m} l$ of methanol-acetonitrile. The methanol-acetonitrile extract $(1 \mu l)$ was subjected to GC analysis for quantification of phenolic metabolites according to the previous method described in a paper by Bieniek ${ }^{14)}$. For urinary phenolic compounds, the following ranges, detection limit: 0.087 to $0.13 \mu \mathrm{mol} /$ mol creatinine, quantitation limit: 0.18 to $0.32 \mu \mathrm{mol} / \mathrm{mol}$ creatinine, relative standard deviation: $3.2-18.4 \%$, and accuracy: 1.6-26.4\%, were achieved.

The creatinine content of each urine sample was analysed by the method based on the Jaffe reaction (Spinreact set, Spain) and determined spectrophotometrically.

\section{Statistical methods}

Statistical analyses were conducted with STATISTICA version 6.0 software. The parameters were characterized as median (measure of location), $5^{\text {th }}$ percentile and $95^{\text {th }}$ percentile (measures of spread) because the assumptions about the shape of the distribution could not have been set. Therefore, we decided to use nonparametric MannWhitney U test to make the comparisons between groups and the Spearman rank correlation coefficient to find the relationship between variables (toluene concentration in air and 2-methylphenol in urine). Only a few variables were log-normally distributed (Chi-Square Goodness- 
Table 1. Median, and $5^{\text {th }}$ and $95^{\text {th }}$ percentile (unit $\mathrm{ppb)}$ of the hydrocarbons in air

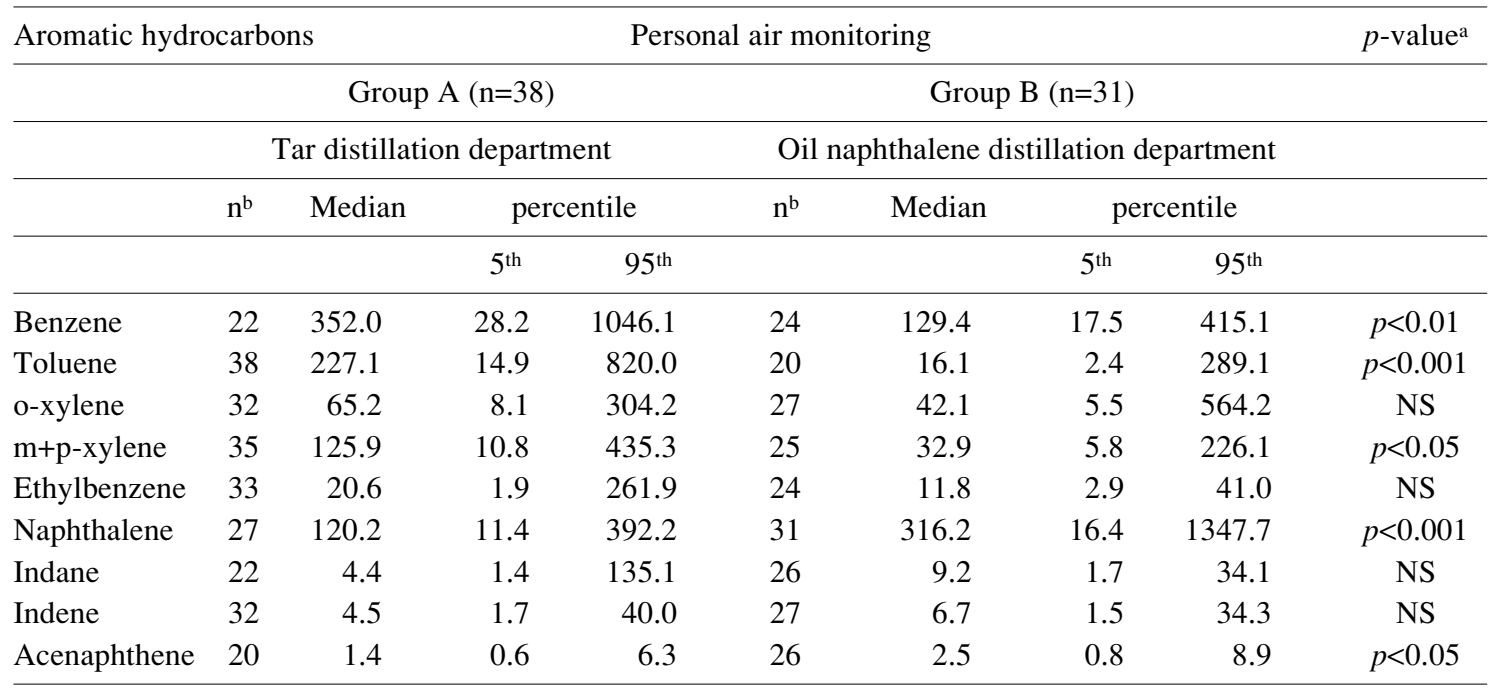

aNS-not significant, ${ }^{b}$ Number of workers in whom the aromatic hydrocarbons were detected above the analytical detection limits

Table 2. Results of biological monitoring of workers: median, $5^{\text {th }}$ and $95^{\text {th }}$ percentile (unit $\mathrm{ppb}$ )

\begin{tabular}{|c|c|c|c|c|c|c|c|c|c|c|c|c|c|}
\hline \multirow[t]{4}{*}{ Metabolites in urine } & \multicolumn{4}{|c|}{ Group A $(n=38)$} & \multicolumn{4}{|c|}{ Group B $(\mathrm{n}=31)$} & $p$ & \multicolumn{4}{|c|}{ Group $C(n=26)$} \\
\hline & \multicolumn{4}{|c|}{ Tar distillation department } & \multicolumn{6}{|c|}{ Oil naphthalene distillation department } & \multicolumn{3}{|c|}{ Control } \\
\hline & \multirow[t]{2}{*}{$\mathrm{n}^{\mathrm{b}}$} & \multirow[t]{2}{*}{ Median } & \multicolumn{2}{|c|}{ percentile } & \multirow[t]{2}{*}{$\mathrm{n}^{\mathrm{b}}$} & \multirow[t]{2}{*}{ Median } & \multicolumn{2}{|c|}{ percentile } & & \multirow[t]{2}{*}{$\mathrm{n}^{\mathrm{b}}$} & \multirow[t]{2}{*}{ Median } & \multicolumn{2}{|c|}{ percentile } \\
\hline & & & $5^{\text {th }}$ & $95^{\text {th }}$ & & & $5^{\text {th }}$ & $95^{\text {th }}$ & & & & $5^{\text {th }}$ & $95^{\text {th }}$ \\
\hline & \multicolumn{4}{|c|}{$\mu \mathrm{mol} / \mathrm{mol}$ creat. } & \multicolumn{5}{|c|}{$\mu \mathrm{mol} / \mathrm{mol}$ creat. } & \multicolumn{4}{|c|}{$\mu \mathrm{mol} / \mathrm{mol}$ creat. } \\
\hline 1-naphthol & 27 & 215.3 & 23.9 & 736.5 & 31 & 321.4 & 36.3 & 901.7 & NS & 25 & 3.6 & 0.8 & 15.3 \\
\hline 2-naphthol & 27 & 126.5 & 11.5 & 345.5 & 31 & 204.6 & 19.5 & 654.3 & NS & 25 & 2.3 & 0.2 & 11.3 \\
\hline 2-methylphenol & 38 & 21.4 & 4.6 & 113.6 & 20 & 13.6 & 7.6 & 56.2 & $p<0.001$ & 25 & 3.4 & 0.5 & 35.6 \\
\hline 2,4-+2,5-dimethylphenol & 129 & 21.3 & 6.8 & 77.6 & 25 & 11.3 & 5.6 & 17.7 & $p<0.001$ & 25 & 3.1 & 0.3 & 27.9 \\
\hline 3,4-dimethylphenol & 25 & 21.8 & 5.6 & 44.6 & 23 & 8.6 & 2.3 & 31.6 & $p<0.001$ & 25 & 3.2 & 0.3 & 19.7 \\
\hline 3,5-dimethylphenol & 23 & 15.6 & 5.7 & 36.5 & 24 & 7.7 & 1.7 & 17.5 & $p<0.001$ & 24 & 3.5 & 0.2 & 28.9 \\
\hline
\end{tabular}

creat.-creatinine, ${ }^{\mathrm{b} N u m b e r}$ of subjects in whom the naphthols and phenols excreted were above the analytical detection limits, $p$ value for group A vs B

of-Fit Test), so analyses on correlations were also carried out after logarithmic transformation of these data, with the Pearson correlation coefficient (naphthalene in air and naphthols in urine). The results were accepted as statistically significant with a $p$-value $<0.05$.

\section{Results}

The time weighted average concentrations of benzene, toluene, xylene isomers, naphthalene, ethylbenzene, indan, indene and acenaphthene detected in the breathing zone air of the exposed workers are summarized in Table 1. It is apparent, that the workers are exposed to relatively low concentrations of aromatic hydrocarbons. For Agroup of workers, concentrations of benzene, toluene, $\mathrm{m}+\mathrm{p}$-xylene in air are higher $(p<0.05)$ than for B-group, whereas concentrations of naphthalene and acenaphthene in air are higher for B-group than for A-group $(p<0.05)$. For groups A and B, no statistically significant differences between average concentrations of o-xylene, ethylbenzene, indane and indene detected in the breathing zone, have been found.

Table 2 summarises the results for urinary naphthols, 2-methylphenol and dimethylphenol isomers for exposed workers (groups A and B) and non-exposed subjects (group C). Urinary metabolite levels were corrected against the creatinine concentration ${ }^{15)}$. In Table 2, significant differences $(p<0.05)$ between average concentrations of urinary metabolites of non-exposed and 


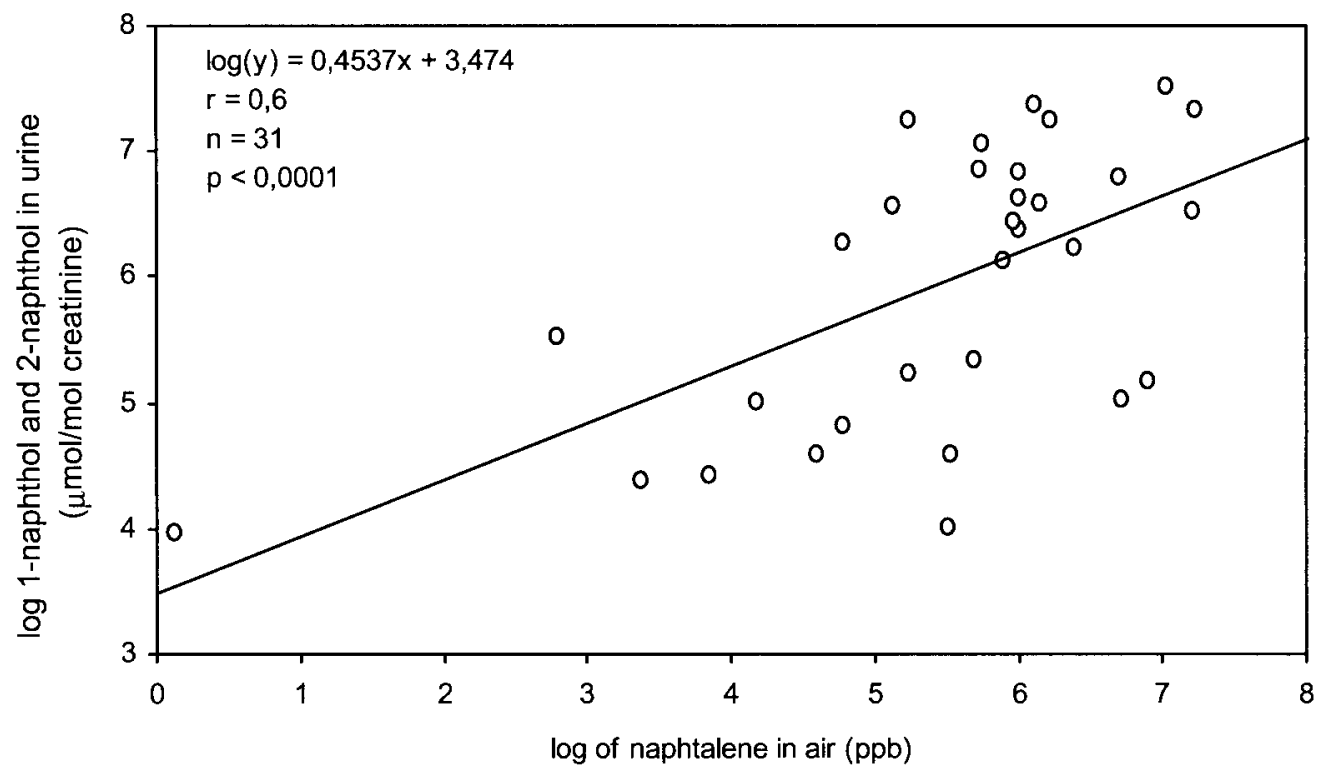

Fig.1. Relation between naphthalene in breathing-zone air and the sum of 1-naphthol and 2-naphthol in shift-end urine of operators of the naphthalene oil distillation.

exposed workers, can be seen. In the exposed group A urinary concentrations of 2-methylphenol and dimethylphenol isomers are significantly higher than in group B $(p<0.001)$, whereas the differences between concentrations of 1-naphthol and 2-naphthol are not statistically significant.

The correlation between the time-weighted average naphthalene exposure and the urinary naphthols level, during the shift, were examined by regression analysis. Figure 1 shows the correlation between the concentration of naphthalene in air and the sum of 1-naphthol and 2naphthol concentrations in shift-end urine of operators of the naphthalene oil distillation. The correlation between the summary concentration of naphthols in urine and the naphthalene concentrations in the breathing zone air are statistically significant at $p<0.001$.

It has been found that concentrations of urinary 2methylphenol and dimethylphenol isomers for groups A are higher $(p<0.05)$ than for group B (Table 2$)$. No significant association was found between urinary 2methylphenol and toluene in air.

\section{Discussion}

During the tar and naphthalene oil distillation processes many chemicals are produced, which can contaminate the environment, e.g. benzene, naphthalene and its homologues, and phenols. According to the current standards of the occupational risk assessment, selected compounds, e.g.: benzene, naphthalene or phenol, have been assigned to study the levels of exposure to different toxic chemicals ${ }^{1,12,16)}$.

Our results show that the time-weighted average concentrations of benzene, toluene, naphthalene, oxylene, $\mathrm{m}+\mathrm{p}$-xylene, ethylbenzene and indene in the breathing zone air (Table 1) are relatively low in comparison to the exposure limits given by ACGIH ${ }^{17)}$. The tar distillation process brings about higher exposure to benzene and its homologues, while higher risk of exposure to naphthalene and acenaphthene has been found at the naphthalene oil distillation process.

Occupational risk from aromatic hydrocarbons of the coke plant workers has been also estimated by the simultaneous determination of 2-methylphenol, dimethylphenol isomers, and naphthols in urine. As can be seen in Table 2, concentrations of the remaining phenol derivatives in urine are also estimated to be low. Nevertheless, significant differences $(p<0.05)$ are found between the concentrations of urinary metabolites detected in the urine of exposed workers (group A and B) and the reference group C. It has been found, that the concentrations of the dimethylphenol isomers in the urine of workers employed at naphthalene oil distillation are lower than in operators at the tar distillation process $(p<0.05)$.

A statistically significantly higher concentration of 2methylphenol in the urine $(p<0.01)$ of workers employed at tar distillation process suggests a higher exposure to toluene or 2-methylphenol in this group than in group B. A survey of the literature shows, that the quantitative relation of urinary 2-methylphenol with time-weighted 
average intensity of exposure to toluene has been investigated by several authors ${ }^{18-21)}$. In our work no statistically significant association was found between urinary 2-methylphenol and toluene in. This result can be partially explained by the metabolism of toluene under conditions of simultaneous exposure of coke plant workers to many chemicals present in large amounts in coal tar. Urinary 2-methylphenol is a very minor metabolite of toluene, accounting for as little as one thousandth of the amount to toluene adsorbed ${ }^{19)}$. According to Inoue ${ }^{22)}$, the urinary 2-methylphenol level is significantly reduced by smoking, drinking, and the two habits combined, therefore it cannot be considered reliable as a biological indicator of low-level exposure to toluene. The presence of 2-methylphenol in the urine of workers might be due to the exposure to toluene ${ }^{21,23,24)}$ as well as to 2-methylphenol. Phenolic compounds comprise approximately $5 \%$ of naphthalene oil and $33 \%$ of carbolic oil ${ }^{25)}$. It is hard to determine the amounts of urinary 2-methylphenol deriving from exposure to toluene and to 2-methylphenol present in air.

Metabolites 2-methylphenol, dimethylphenols and naphthols, were present in the urine of non-exposed subjects. All subjects were smokers and smoking is a known source of naphthols ${ }^{8)}$ and fenols ${ }^{26,27)}$. The phenolic compounds found in the control group may reflect the uptake of small amounts of phenol derivatives from environmental sources. The reference group (C) comprises subjects who live in the same area as the workers, but who are not occupationally exposed. Phenols in ambient air have been extensively monitored in the highly industrialized Upper Silesia region of Poland $^{28)}$. In 1997-1998 they ranged from 1.3 to $3.9 \mathrm{ppb}$, the highest values being recorded in the areas of greatest industrial concentration. Aromatic hydrocarbons are most often present in the environment as components of complex mixtures. Aromatic hydrocarbons from the petrochemical effluents ranged between 77 and $93 \%$.

Naphthalene tends to be the predominant airborne compound in the processing and handling of coal tar products $^{1,16)}$, in iron foundry ${ }^{29)}$ and in creosote impregnation plants ${ }^{30,31)}$ Naphthalene is metabolized almost exclusively to 1-naphthol and 2-naphthol ${ }^{16)}$. Detection of naphthols in the urine is the most widely used indicator of naphthalene exposure ${ }^{32,33)}$

As seen in Table 2, concentrations of naphthol isomers are higher in the urine of workers engaged in the naphthalene oil distillation than in the tar distillation departments, but are not statistically significant. Differences between the concentrations of 1-naphthol and 2-naphthol detected in the urine of exposed and nonexposed subjects are statistically significant. Earlier investigations were able to determine simultaneously the presence of 1-naphthol and 2-naphthol in the urine of workers employed at the naphthalene oil distillation process in a coke plant ${ }^{32)}$. It was found that the concentrations of the naphthols were significantly higher than in the present results.

The data have shown that for most of the biomarkers studied, significant differences are found between the nonexposed subjects and those occupationally exposed to low concentrations of hydrocarbons. Biological monitoring of hydrocarbons provides better estimation of the absorbed substances than measurements of the corresponding contaminants in air, because the skin can be an alternative route of exposure.

\section{Conclusions}

In conclusion, the GC/FID analysis is useful for environmental and toxicological studies. Operators at the tar and naphthalene oil distillation processes are simultaneously exposed to a mixture of aromatic hydrocarbons. Concentrations of the hydrocarbons have been found to be relatively low in comparison to the exposure limits. Occupational risk from aromatic hydrocarbons in coke plant workers seems to result mainly from the diversity of the compounds identified in an occupational environment.

Acknowledgments: The authors wish to thank the Managing Board of the Zabrze Cokery Plant (Poland) for their kind permission to continue research.

\section{References}

1) International Agency for Research on Cancer: IARC Monographs on the Evaluation of the Carcinogenic Risk of Chemicals to Humans: Polynuclear Aromatic Compounds, Part 3, Industrial Exposure in Aluminium Production, Coal Gasification Coke Production, and Iron and Steel Founding. Lyon: IARC, 1984: 65-131

2) L Drummond, R Lack, AS Afacan and HK Wilson: Biological monitoring of workers exposed to benzene in the coke oven industry. Brit J Ind Med 45, 256-261 (1988)

3) G Grimmer, G Dettbarn and J Jacob: Biomonitoring of polycyclic aromatic hydrocarbons in highly exposed coke plant workers by measurement of urinary phenanthrene and pyrene metabolites (phenols and dihydrodiols). Int Arch Occup Environ Health 65,189199 (1993)

4) PR Romundstad, A Ronneberg, HL Leira and T Bye: Health survey of former workers in a Norwegian coke plant: part 1. Estimation of histirical exposures. Occup Environ Med 55, 616-621 (1998)

5) E Neiminen and $P$ Heikkila : Simultaneous determination of phenol, cresols, and xylenols in workplace air using a polystyrene-divinylbenzene column and electrochemical detection. J Chromatogr 360, 271-278 (1986)

6) M Ogata and T Taguchi: Simultaneous determination of urinary creatinine and metabolites of toluene, xylene, styrene, ethylbenzene and phenol by automated high 
performance liquid chromatography. Int Arch Occup Health 61,131-140 (1988)

7) R Tardif, S Lapare, GL Plaa and J Brodeur: Effect of simultaneous exposure to toluene and xylene on their respective biological exposure indices in humans. Int. Arch Occup Environ Health 63, 279-284 (1991)

8) P Heikkila, M Luotamo, L Pyy and V Riihimaki: Urinary 1-naphthol and 1-pyrenol as indicators of exposure to coal tar products. Int Arch Occup Environ Health 67, 211-217 (1995)

9) O Inoue, K Seiji, T Kawai, Ch Jin, S-X Cai, L Che, Q$\mathrm{S}$ Qu, T Zhang and M Ikeda: Excretion of methylhippuric acids in urine of workers exposed to a xylene mixtures comparison among three xylene isomers and toluene. Int Arch Occup Environ Health 64, 533-539 (1993)

10) I Lehmann, M Rehwagen, U Diez, A Seiffart, U RolleKampczyk, M Richter, H Wetzig, Borte and O Herbarth: Enhanced in vivo $\operatorname{lgE}$ production and T cell polarization toward the type 2 phenotype in association with indoor exposure to VOC: results of the LARS study. Int J Hyg Environ Health 204, 211-221 (2001)

11) CE Gomez, L Contenoto and AE Carsen: Toxicity tests to assess pollutants removal during wastewater treatment and the quality of receiving waters in Argentina. Environ Toxicol 16, 217-224 (2001)

12) C-C Lee, M-R Chen, T-S Shih, P-J Tsai, C-H Lai and S-H Liou: Exposure assessment on volatile organic compounds (VOCs) for tollway station workers via direct and indirect approaches. J Occup Health 44, 294 $300(2002)$

13) G Bieniek: Simultaneous determination of ethylbenzene, indan, indene and acenaphthene in air by capillary gas chromatography. J Chromatogr A 891, 361-365 (2000)

14) G Bieniek: Simultaneous determination of phenol, cresol, xylenol isomers and naphthols in urine by capillary gas chromatography. J Chromatogr B 682, 167-172 (1996)

15) L Alessio, A Berlin, A Dell Orto, F Toffoletto and I Ghezzi: Reliability of creatinine as a parameter used to adjust values of urinary biological indicators. Int Arch Occup Environ Health 55, 99-106 (1985)

16) US Department of Health and Human Services: Toxicological profile for naphthalene, 1methylnaphthalene and 2-methylnahthalene. Agency for Toxic Substances and Disease Registry, Public Health Service, DHHS 1995

17) American Conference of Govemmental Industrial Hygienist: Threshold Limit Values (TLV) for Chemical Substances and Physical Agents Biological Exposure Indices (BEI). Cincinnati.(ACGIH) 1997

18) P Apostoli, F Brugnone, L Perbellini, V Cocheo, ML Bellomo and R Silversti: Biomonitoring of occupational toluene exposure. Int Arch Occup Environ Health 50, 153-168 (1982)

19) K Hasegawa, S Shiojima, A Koizumi and M Ikeda: Hippuric acid and o-cresol in the urine of workers exposed to toluene. Int Arch Occup Environ Health 52, 197-208 (1983)
20) E DeRosa, GB Bartolucci, M Sigon, R Callegaro, L Perbellini and F Brugnone: Hippuric acid and orthocresol as biological indicators of occupational exposure to toluene. Am J Ind Med 11, 529-537 (1987)

21) CH Pierce, RL Dills, MS Morgan, P Vicini and DA Kalman: Biological monitoring of controlled toluene exposure. Int Arch Occup Environ Health 71, 433-444 (1998)

22) O Inoue, K Seiji, T Watanabe, $Z$ Chen, M-Y Huang, X-P Xu, X Qiao and M Ikeda: Effects of smoking and drinking habits on urinary o-cresol excretion after occupational exposure to toluene vapor among Chinese workers. Am J Ind Med 25, 697-708 (1994)

23) Nise G: Urinary excretion of o-cresol and hippuric acid after toluene exposure in rotogravure printing. Int Arch Occup Environ Health, 63, 377-381 (1992)

24) M Døssing, JB Baelum, SH Hansen, GR Lundqvist and NT Andersen: Urinary hippuric acid and orthocresol excretion in man during experimental exposure to toluene. Br J Ind Med. 40, 470-473 (1983)

25) G Bieniek: Urinary excretion of phenols as an indicator of occupational exposure in the coke plant industry. Int Arch Occup Environ Health 70, 334-340 (1997)

26) BA Tomkins, RA Jenkins, WH Griest, RR Reagan and SK Holladay: Liquid chromatographic determination of phenol and cresols in total particulate matter of cigarette smoke. J Assoc Off Anal Chem 67, 919-923 (1984)

27) EJ Nanni, ME Lovette, RD Hicks, KW Fowler, MF Borgerding: Separation and quantitation of phenolic compounds in mainstream cigarette smoke by capillary gas chromatography with mass spectrometry in the selected ion mode. J Chromatogr 505: 365-374 (1990)

28) Sanitary Epidemiological Station, Katowice. Air pollution in the Katowice voivodeship in 1997-1998. Regional Sanitary Epidemiological Station, Katowice, Poland, 1998

29) AM Hansen, O Omland, OM Poulsen, D Sherson, T Sisgaard, JM Christensen and E Overgaard: Correlation between work process-related exposure to polycyclic aromatic hydrocarbons and urinary levels of $\alpha$ naphthol, $\beta$-naphthylamine and 1-hydroxypyrene in iron foundry workers. Int Arch Occup Environ Health 65, 385-394 (1994)

30) P Heikkila, M Luotamo and V Riihimaki: Urinary 1naphthol excretion in the assessment of exposure to creosote in an impregnation facility. Scand J Work Environ Health 23, 199-205 (1997)

31) M Bouchard, L Pinsonneault, C Tremblay and J-P Weber: Biological monitoring of environmental exposure to polycyclic aromatic hydrocarbons in subjects living in the vicinity of a creosote impregnation plant. Int. Arch Occup Environ Health 74, 505-513 (2001)

32) M Yang, M Koga, T Katoh and T Kawamoto: A study for the proper application of urinary naphthols, new biomarkers for airborne polycyclic aromatic hydrocarbons. Arch Environ Contam Toxicol 36, 99108 (1999)

33) Bieniek G: Urinary naphthols as an indicator of exposure to naphthalene. Scand J Work Environ Health 23, 414-420 (1997) 